\title{
Chemically-Passive Suppression of Laminar Premixed Hydrogen Flames in Microgravity
}

\author{
Li Qiao ${ }^{*}$, Yongxian $\mathrm{Gu}^{\dagger}$, Werner J.A. Dahm ${ }^{\ddagger}$, and Gerard M. Faeth ${ }^{\S}$ \\ The University of Michigan, Ann Arbor, MI, 48109-2140, USA \\ and \\ Elaine S. Oran ${ }^{* *}$ \\ Naval Research Laboratory, Washington, D.C., 20375, USA
}

\begin{abstract}
Effects of chemically-passive fire suppressants on laminar premixed hydrogen flames were investigated by combined use of microgravity experiments and computations. The experiments used a short-drop free-fall laboratory facility that provides at least $450 \mathrm{~ms}$ of $10^{-2} \mathrm{~g}$. Near-limit laminar burning velocities were measured for outwardly propagating spherical stoichiometric hydrogen-air flames with varying concentrations of $\mathrm{He}, \mathrm{Ar}, \mathrm{N}_{2}$ and $\mathrm{CO}_{2}$ as suppressants. Burning velocities were also computed using the steady, onedimensional laminar premixed flame code PREMIX. Both measured and computed results showed the suppressants to increase in effectiveness in the order $\mathrm{He}, \mathrm{Ar}, \mathrm{N}$ differences in effectiveness are shown to result from increased quenching of reactions by the increased specific heat due to the suppressant and from changes in the transport rates near the flame. The addition of suppressant generally decreased Markstein numbers, which made the flames more susceptible to preferential-diffusion instability. This effect increases flame speeds and tends to counteract the effect of suppressant to reduce laminar burning velocities. The concentration needed for each suppressant to prevent flame propagation was also determined. Far from this flammability limit, agreement between measured and computed laminar burning velocities was good, but for near-limit flames the computed velocities were significantly lower than measured values. These near-limit dfferences may be due to thirdbody recombination rates for $\mathrm{H}+\mathrm{O}_{2}+\mathrm{M}=\mathrm{HO}_{2}+\mathrm{M}$ reactions, and in particular to the thirdbody chaperon efficacy of various species $M$.
\end{abstract}

\section{Nomenclature}

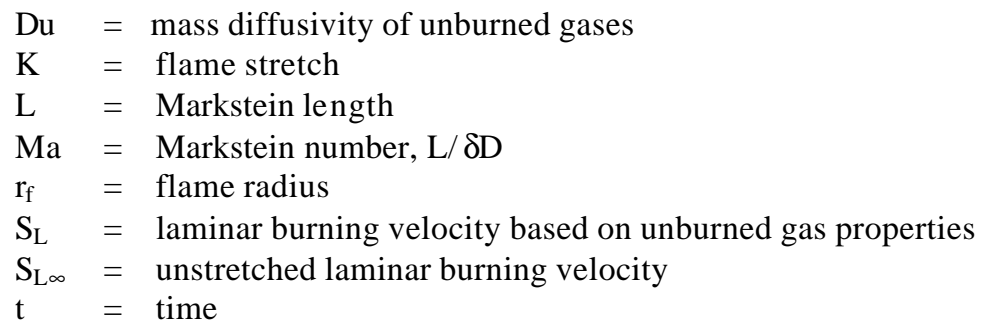

\footnotetext{
* Graduate Student Research Assistant, Department of Aerospace Engineering. lqiao@umich.edu

${ }^{\dagger}$ Graduate Student Research Assistant, Department of Aerospace Engineering.

${ }^{\ddagger}$ Professor \& Head, Laboratory for Turbulence and Combustion (LTC), Department of Aerospace Engineering. Fellow AIAA.

$\S$ A.B. Modine Distinguished University Professor, Department of Aerospace Engineering. Fellow AIAA.

** Senior Scientist, Laboratory for Computational Physics and Fluid Dynamics. Fellow AIAA.
} 


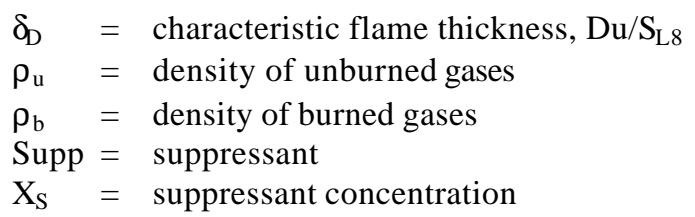

\section{Introduction}

Long-duration space missions, including trips to the Moon and Mars, present substantially increased risks of accidental fires, and as a result the development of effective fire-safety systems for spacecraft environments will be critical to such missions. Chemically-active flame suppressants such as Halons have been very successful in applications where effective control of unwanted fires is need. In fact, many experimental and computational studies have been undertaken to gain a better understanding of the mechanism of flame suppression of the chemically active halons and their potential replacement ${ }^{1-4}$. These studies have shown that chemically active suppressants are unusually effective because they interrupt the chemical pathway of fuel oxidation. Unfortunately, chemically active suppressants often generate reaction products that can be dangerous to health of astronauts and life-support systems of spacecraft. Consequently, chemically-passive suppressants are potentially more suitable for such long-duration missions. The present study thus examines the effectiveness of various chemically-passive suppressants on flame propagation under microgravity conditions and spacecraft environments.

Studies to gain an understanding of the inhibiting effects of suppressants on flames have been performed in premixed $^{5-6}$ and diffusion ${ }^{7-8}$ flames. However, these studies are based on the standard normalgravity tests, in which the modeled flame propagation and extinction mechanism are distinctly different from those in low-gravity flames. Specifically, studies ${ }^{9-11}$ have shown low-gravity flames to have broader flammability limits than do comparable flames in normal gravity. The reduction of buoyancy with reduced gravity makes weak near-limit flames in microgravity more difficult to extinguish, and for this reason conventional normal-gravity tests cannot provide effective guidelines for suppressant effectiveness on flammability limits in microgravity environments.

Here we present results for suppressant effects on flames by studying outwardly-propagating spherical laminar premixed hydrogen flames in microgravity. Although most practical flames are turbulent, turbulent flames are difficult to study because experimental conditions are substantially complicated by the need to describe turbulence properties. In addition, turbulent flames cause turbulence-induced stretching and quenching, making them less conservative indicators of flame extinction than corresponding laminar flames. Laminar flames are relevant to practical turbulent flames based on widely-accepted laminar flamelet concepts of turbulent flames. Premixed flames have geometries and properties that simplify the control of experimental variables and the interpretation of experimental results. They develop sufficiently fast that their propagation characteristics can be measured in the laboratory using a small, short-drop, free-fall microgravity facility. Moreover, hydrogen-oxygen chemical kinetics play a fundamental role for combustion of all hydrocarbons in air, and numerical solutions of the underlying kinetic mechanism are considered relatively reliable. Furthermore, results from the hydrogen-oxygen system provide conservative estimates for suppressant effectiveness, since such flames are the most difficult to extinguish among combustibles of practical interest

One of the distinguishing features of laminar premixed flames is that they have a characteristic propagation rate, commonly called laminar burning velocity. Laminar burning velocities are of great importance in many areas of the combustion science, e.g., they are used to determine the ignition delay time, the thickness of the wall quench layers and the minimum ignition energy in combustion engines. They are also commonly used to validate chemical kinetic schemes. Therefore, the accurate measurements on laminar burning velocities play a key role in the process of understanding the suppression properties of suppressants on flames. Lots of studies have shown that laminar burning velocities and structures of laminar premixed flames are significantly affected by flame/stretch interactions ${ }^{12-17}$. To deal this problem, we use unstretched laminar burning velocities to characterize the intensity of combustion of the flames and use Markstein numbers to characterize the sensitivity of flames to the effects of stretch in the present investigation. Fortunately, outwardly propagating spherical laminar premixed flames provide a straightforward determination of unstretched laminar burning velocities and Markstein numbers ${ }^{18-20}$. 
A previous study ${ }^{18}$ has reported results for the effectiveness of various diluents as chemically-passive flame suppressants under normalgravity conditions. The diluents considered were inert gases, specifically $\mathrm{He}, \mathrm{Ar}, \mathrm{N}_{2}$ and $\mathrm{CO}_{2}$, chosen to allow separate identification of the relative effects of dilution, heat capacity, and transport properties on suppressant effectiveness. That study examined flame propagation velocities in normal gravity for suppressant concentrations below $40 \%$ volume fraction in the reactant mixture. For such comparatively low suppressant concentrations, the resulting flames were sufficiently fast that gravity had a negligible effect on the flame propagation. However, as the suppressant volume fraction is increased above $40 \%$ and the extinction limit is approached, normalgravity flames become greatly affected by buoyant distortion. As a result, conducting nearlimit flame-suppression experiments under microgravity conditions is essential for determining the true flammability limits of suppressed flames for spacecraft environments.

Therefore the purpose of the present study is to extend previous work by investigating the effects of chemicallypassive suppressants on the near-limit properties of laminar premixed hydrogen fla mes in microgravity. First, we introduce a novel short-drop free-fall facility that allows measurement of near-limit flame properties without the disruptive effects of buoyancy. Second, unstretched laminar burning velocities and Markstein numbers are measured for diluted stoichiometric hydrogen-air flames at atmospheric pressure using $\mathrm{He}, \mathrm{Ar}, \mathrm{N}_{2}$ and $\mathrm{CO}_{2}$ as suppressants. Corresponding results are also obtained for suppression of stoichiometric hydrogen flames in an atmosphere consisting of $30 \%$ oxygen and $70 \%$ nitrogen by volume at a pressure of $0.7 \mathrm{~atm}$, which is the prescribed spacecraft environment for crew conditioning prior to external vehicular activities (EVA). Third, for each suppressant and both atmospheres, measured values of the suppressant volume fraction needed to extinguish the flames are determined by extrapolating the near-limit laminar burning velocities to zero. Finally, the near-limit unstretched laminar burning velocities measured in both normal-air and EVA atmospheres are compared with corresponding computed values. We analyze possible reasons for the discrepancies between experiments and computations.

\section{Experiment Description}

\section{A. Apparatus}

Figure 1 shows key components of the short-drop free-fall facility assembled for this investigation in the Microgravity Combustion Laboratory at the University of Michigan. The facility consists of a support tower, a freefalling spherical combustion chamber, a deceleration box, and shadowgraph optics that record the flame propagation as the chamber falls. The free-fall chamber, which has an inside diameter of $360 \mathrm{~mm}$ and can be operated at pressures from vacuum to $34 \mathrm{~atm}$, is held at the top of the tower by an electromagnet before being dropped. As the chamber is released, a Hall-effect sensor detects the motion and sends a trigger pulse to a timer. After a short delay to allow oscillations from the chamber release to decay to required levels, a timer pulse triggers a high-voltage spark generator connected to electrodes that ignite the mixture. A second pulse triggers a high-speed digital video camera that records the flame propagation within the free-falling chamber. The free-fall duration can be made as long as $750 \mathrm{~ms}$ by setting the vertical position of a deceleration box below the chamber. In the present experiments, a onemeter free-fall distance is used to provide $450 \mathrm{~ms}$ of $10^{-2} \mathrm{~g}$ reduced gravity. After each experiment, the combustion chamber is vented and purged with air to cool it down prior to being recharged with the desired atmosphere and hoisted up the tower for the next test.

A high-speed shadowgraph system records the flame during the fall. As indicated in Fig. 1, light from a continuous $100 \mathrm{~W}$ short arc-length mercury lamp is reduced by a neutral density filter and reflected from a concave mirror to form a parallel beam. Using three first surface mirrors, one fixed on the drop tower and two attached on either side of the free-fall chamber, the parallel light beam propagates through two 100 mm diameter quartz windows mounted on the each side of the chamber, and then back up the tower toward the video camera. The beam passes through a lens that directs the image onto a Phantom high-speed digital video camera that records 1000 images per second.

The reactant mixture is prepared in the spherical combustion chamber by adding gases at appropriate partial pressures to reach the desired reactant mixture and test pressure. The reactants are mixed for 5-10 minutes using a small metal fan in the chamber, and the fan-induced motion is allowed to decay for at least 30 minutes before 
ignition. The flame is ignited by a spark at the center of the chamber from two electrodes consisting of $250 \mu \mathrm{m}$ diameter tungsten wires having free lengths of $40 \mathrm{~mm}$. The spark gap is adjusted from 0.5-3.0 mm, with larger gaps used to ignite flames having relatively small laminar burning velocities that require larger ignition energies. The spark energy is supplied by a high-voltage capacitive discharge circuit with an adjustable $0-30 \mathrm{kV}$ voltage and a discharge time of roughly $5 \mu \mathrm{s}$. The spark gap and spark energy are adjusted be to as close as possible to the minimum ignition energies.

\section{B. Data Reduction}

Present measurements were restricted to flames with diameters $10 \mathrm{~mm}<d<$ $60 \mathrm{~mm}$, with the upper limit imposed so that the volume of burned gas is always less than $0.5 \%$ of the total chamber volume. As a result, the chamber pressure remains constant within $0.7 \%$ throughout the observation period, consistent with previous measurements of laminar premixed flame properties ${ }^{18-20}$. The lower limit on flame diameter avoids ignition disturbances and ensures that the characteristic flame thickness $\delta_{\mathrm{D}}$ and flame radius $r_{f}$ satisfy $\delta_{\mathrm{D}} / r_{f} \ll<1$, so that effects of flame curvature and thickness are negligible. This is also consistent with previous measurements ${ }^{18-20}$. Under these assumptions, quasi-steady expressions for the laminar burning velocity and flame stretch are given ${ }^{14}$ by

$S_{L}=\frac{\rho_{b}}{\rho_{u}} \frac{d r_{f}}{d t}, K=\frac{2}{r_{f}} \frac{d r_{f}}{d t}$

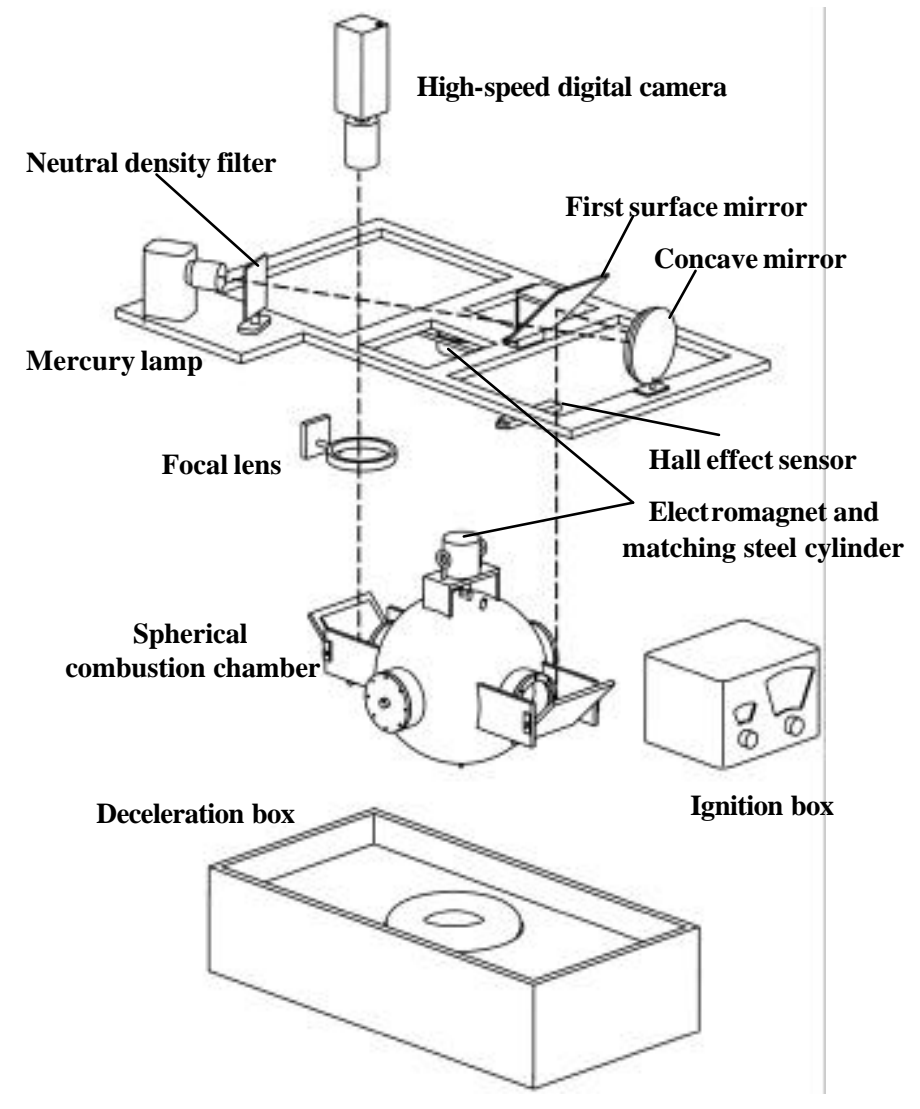

Figure 1. Schematic diagram of the short-drop free-fall microgravity facility.

Here $S_{L}$ is the observed flame propagation speed into the unburned gas and $K$ is the flame stretch. Both are related to the change in flame radius $r_{f}$ with time $t$. The density ratio $\rho_{b} / \rho_{u}$ was obtained from CET93 assuming adiabatic constant-pressure combustion with chemical equilibrium in the combustion products ${ }^{8}$ and the same volume fractions of elements in the unburned and burned gases ${ }^{18-20}$. The flame radius $r_{f}(t)$ was measured from the shadowgraph images along the direction perpendicular to the spark electrodes, where disturbances of the flame surface by the electrodes are minimal. Final results were averaged over measurements from three to five tests at each condition, with $95 \%$ confidence intervals characterizing uncertainties in the reported values.

\section{Data Correlation}

From Markstein ${ }^{13}$ and Clavin ${ }^{15}$, the laminar burning velocity $S_{L}$ is related to the flame stretch $K$ for small to moderate values of curvature and stretch as

$S_{L}=S_{L \infty}-L K$ 
where $S_{L \infty}$ is the laminar burning velocity for an unstretched planar flame. The Markstein length $L$ is a measure of the flame response to the stretch rate $K$, and can be either positive (preferential-diffusion stable) or negative (preferential-diffusion unstable), depending on the reactants. The Markstein length is proportional to a characteristic flame thickness based on mass diffusivity of the deficient reactant, $\delta_{D}$, so that a dimensionless Markstein number can be defined as

$$
M a=L / \delta_{D}=L /\left(D_{u} / S_{L \infty}\right)=L S_{L \infty} / D_{u}
$$

Here, the characteristic flame thickness $\delta_{D}$ is defined as the ration of mass diffusivity $D_{u}$ to the unstretched laminar burning velocity $S_{L_{\infty}}$. The unstretched laminar burning velocities $S_{L_{\infty}}$ were obtained by extrapolating the measured stretched laminar burning velocities $S_{L}(K)$ from $(1 a, b)$ to zero stretch. Since this study involves relatively slow nearlimit flames at low values of stretch, the effects of preferential diffusion are small. All measurements reported herein were made before any flame instabilities were observed. The resulting uncertainty in the measured $S_{L \infty}$ values based on the $95 \%$ confidence intervals is typically below $10 \%$, with the largest uncertainties corresponding to extremely slow thick flames, for which the radius is more difficult to measure. The uncertainty in Ma values is generally less than $25 \%$ for $|\mathrm{Ma}|>1$ and less than $25 \% /|\mathrm{Ma}|$ for $|\mathrm{Ma}|<1$.

\section{Test Conditions}

Experimental conditions are summarized in Table 1 and 2. Experimental conditions for $\mathrm{H} /$ air/suppressant flames, summarized in Table 1, seek to representative of human habitation conditions on Earth at various altitudes, as follows: reactant mixtures at room temperature $(298 \pm 0.5 \mathrm{~K})$, a fuel-equivalence ratio of 1.0 , a pressure of 1.0 atm, and suppressant concentrations from $40 \%$ to the extinction limit with helium, argon, nitrogen and carbon dioxide as suppressants. Experimental conditions for $\mathrm{H}_{2} / 30 \%$

Table 1. $\mathrm{H}_{2} /$ Air/Suppressant Laminar Premixed Flame Test Conditions ${ }^{\text {a }}$

\begin{tabular}{|c|c|c|c|c|}
\hline Supp & $\mathrm{X}_{\mathrm{s}}$ & $\rho_{\mathrm{u}} / \rho_{\mathrm{b}}$ & $\begin{array}{c}\mathrm{S}_{\mathrm{L}_{\infty}} \\
(\mathrm{cm} / \mathrm{s})\end{array}$ & $\mathrm{Ma}$ \\
\hline \multicolumn{5}{|c|}{$\mathrm{p}=1.0 \mathrm{~atm} \phi=1.0, \mathrm{D}_{\mathrm{u}}=158.7 \mathrm{~mm}^{2} / \mathrm{s}:$} \\
\hline $\mathrm{He}$ & 0.40 & 5.79 & 117.0 & 0.9 \\
\hline $\mathrm{He}$ & 0.56 & 4.98 & 55.9 & 0.9 \\
\hline $\mathrm{He}$ & 0.60 & 4.71 & 45.0 & 1.1 \\
\hline $\mathrm{He}$ & 0.64 & 4.43 & 29.5 & 0.9 \\
\hline \multicolumn{5}{|c|}{$\mathrm{p}=1.0 \mathrm{~atm} \phi=1.0, \mathrm{D}_{\mathrm{u}}=75.5 \mathrm{~mm}^{2} / \mathrm{s}:$} \\
\hline $\mathrm{Ar}$ & 0.40 & 5.75 & 76.0 & 0.2 \\
\hline Ar & 0.48 & 5.47 & 55.4 & 0.1 \\
\hline Ar & 0.56 & 4.98 & 34.9 & -0.3 \\
\hline Ar & 0.64 & 4.37 & 20.0 & -0.2 \\
\hline $\mathrm{Ar}$ & 0.68 & 4.11 & 12.3 & -0.2 \\
\hline $\mathrm{Ar}$ & 0.72 & 3.79 & 6.3 & -0.3 \\
\hline \multicolumn{5}{|c|}{$\mathrm{p}=1.0 \mathrm{~atm}, \phi=1.0, \mathrm{D}_{\mathrm{u}}=72.9 \mathrm{~mm}^{2} / \mathrm{s}:$} \\
\hline $\mathrm{N}_{2}$ & 0.40 & 5.13 & 48.0 & -1.0 \\
\hline $\mathrm{N}_{2}$ & 0.48 & 4.67 & 29.6 & -0.7 \\
\hline $\mathrm{N}_{2}$ & 0.52 & 4.42 & 23.5 & -0.8 \\
\hline $\mathrm{N}_{2}$ & 0.56 & 4.17 & 17.5 & -0.6 \\
\hline $\mathrm{N}_{2}$ & 0.60 & 3.92 & 11.9 & -0.1 \\
\hline $\mathrm{N}_{2}$ & 0.64 & 3.65 & 5.7 & -0.4 \\
\hline \multicolumn{5}{|c|}{$\mathrm{p}=1.0 \mathrm{~atm} \phi=1.0, \mathrm{D}_{\mathrm{u}}=59.9 \mathrm{~mm}^{2} / \mathrm{s}:$} \\
\hline $\mathrm{CO}_{2}$ & 0.40 & 4.36 & 18.0 & -0.6 \\
\hline $\mathrm{CO}_{2}$ & 0.44 & 4.10 & 11.0 & -0.7 \\
\hline $\mathrm{CO}_{2}$ & 0.48 & 3.87 & 6.6 & -0.5 \\
\hline
\end{tabular}

${ }^{\mathrm{a}}$ Initial mixture temperature of $298 \pm 0.5 \mathrm{~K}$. $\mathrm{O}_{2}+70 \% \mathrm{~N}_{2}$ /suppressant flames are summarized in Table 2, involve EVA-preparation conditions for spacecraft, as follows: reactant mixture at room temperature $(298 \pm 0.5 \mathrm{~K})$ and a pressure of $0.7 \mathrm{~atm}$, a fuel equivalence ratio of unity, and suppressant concentrations of $40 \%$ to the extinction limit with nitrogen and carbon dioxide as suppressants.

Table 2. $\mathrm{H}_{2} / \mathrm{EVA} /$ Suppressant Laminar Premixed Flame Test Conditions ${ }^{a}$

\begin{tabular}{ccccc}
\hline Supp & $\mathrm{X}_{\mathrm{s}}$ & $\rho_{\mathrm{u}} / \rho_{\mathrm{b}}$ & $\begin{array}{c}\mathrm{S}_{\mathrm{L} \infty} \\
(\mathrm{cm} / \mathrm{s})\end{array}$ & $\mathrm{Ma}$ \\
\hline $\mathrm{p}=0.7 \mathrm{~atm}, \phi=1.0, \mathrm{D}_{\mathrm{u}}=104.1 \mathrm{~mm}^{2} / \mathrm{s}:$ \\
$\mathrm{N}_{2}$ & 0.60 & 4.65 & 33.3 & -0.5 \\
$\mathrm{~N}_{2}$ & 0.64 & 4.34 & 25.1 & -0.4 \\
$\mathrm{~N}_{2}$ & 0.68 & 4.01 & 14.2 & -0.8 \\
$\mathrm{~N}_{2}$ & 0.72 & 3.68 & 7.9 & -0.6 \\
$\mathrm{~N}_{2}$ & 0.74 & 3.50 & 3.3 & -0.5 \\
$\mathrm{p}=0.7$ atm $\phi=1.0, \mathrm{D}_{\mathrm{u}}=85.6 \mathrm{~mm}^{2} / \mathrm{s}:$ & \\
$\mathrm{CO}_{2}$ & 0.40 & 5.06 & 48.0 & -0.3 \\
$\mathrm{CO}_{2}$ & 0.44 & 4.85 & 25.9 & -0.7 \\
$\mathrm{CO}_{2}$ & 0.48 & 4.57 & 16.7 & -0.8 \\
$\mathrm{CO}_{2}$ & 0.52 & 4.29 & 13.1 & -0.7 \\
$\mathrm{CO}_{2}$ & 0.56 & 4.01 & 8.0 & -0.5 \\
$\mathrm{CO}_{2}$ & 0.60 & 3.75 & 3.9 & -0.4 \\
\hline Initial mixture temperature of $298 \pm 0.5 \mathrm{~K}$.
\end{tabular}




\section{Computational Method}

Numerical calculations of the corresponding plane unstretched premixed flames were carried out using the steady, one-dimensional laminar premixed flame code PREMIX. This algorithm allows for multicomponent diffusion, thermal diffusion, variable thermochemical properties and variable transport properties, which is a sufficiently accurate treatment of transport for present purposes, as discussed in Ref. 19. The numerical algorithm employs self-adaptive gridding to deal with regions where property gradients are large. The computational grid in space was varied to insure numerical accuracy. Present calculations used the updated comprehensive kinetic model for hydrogen combustion due to Li et al. ${ }^{22}$. CHEMKIN was used as a preprocessor to determine thermochemical and transport properties from the database of Kee et al. ${ }^{23}$, except for $\mathrm{HO}_{2}$, for which the recommendations of Kim et $a l .{ }^{24}$ were used. Previous studies ${ }^{18-20}$ have shown that the effects of radiative heat losses for the fast-propagating hydrogen flames were small comparing to the total heat release rate. However, radiation effects can be significant at reduced gravity for near-limit flames ${ }^{9}$. In fact, increasing dilution of hydrogen flames can lead to extinction due to radiative heat loss if the experimental apparatus are sufficiently large ${ }^{31}$. Therefore, an optically thin model was used to calculate the radiative heat loss from $\mathrm{CO}_{2}$ and $\mathrm{H}_{2} \mathrm{O}$ in the present study. Planck absorption coefficients were taken from Kuznetsov and Sabelnikov ${ }^{25}$. The resulting computed unstretched burning velocities $S_{L \infty}$ were compared for each suppressant type and concentration with the corresponding measured values obtained as described above. The predicted flame structures were also compared for unsuppressed and suppressed flames. Finally, the sensitivity of computed laminar burning velocities to the reactions of the present chemical kinetic mechanism was evaluated.

\section{Results and Discussion}

\section{A. Effects of Gravity}

In previous 1-g experiments ${ }^{4}$, for undiluted or moderately-diluted mixtures corresponding to $S_{L \infty}>20 \mathrm{~cm} / \mathrm{s}$, the observed flame front remained spherical throughout the measurement. In such cases, the laminar burning velocities obtained in 1-g and $\mu$-g experiments are essentially the same. However for more highly-diluted slower-burning mixtures, flames in 1-g become noticeably buoyant, with the flame reaching the top of the chamber before the bottom. At very high dilution levels corresponding to slowly-burning near-limit mixtures, a flame at $1 \mathrm{~g}$ cannot
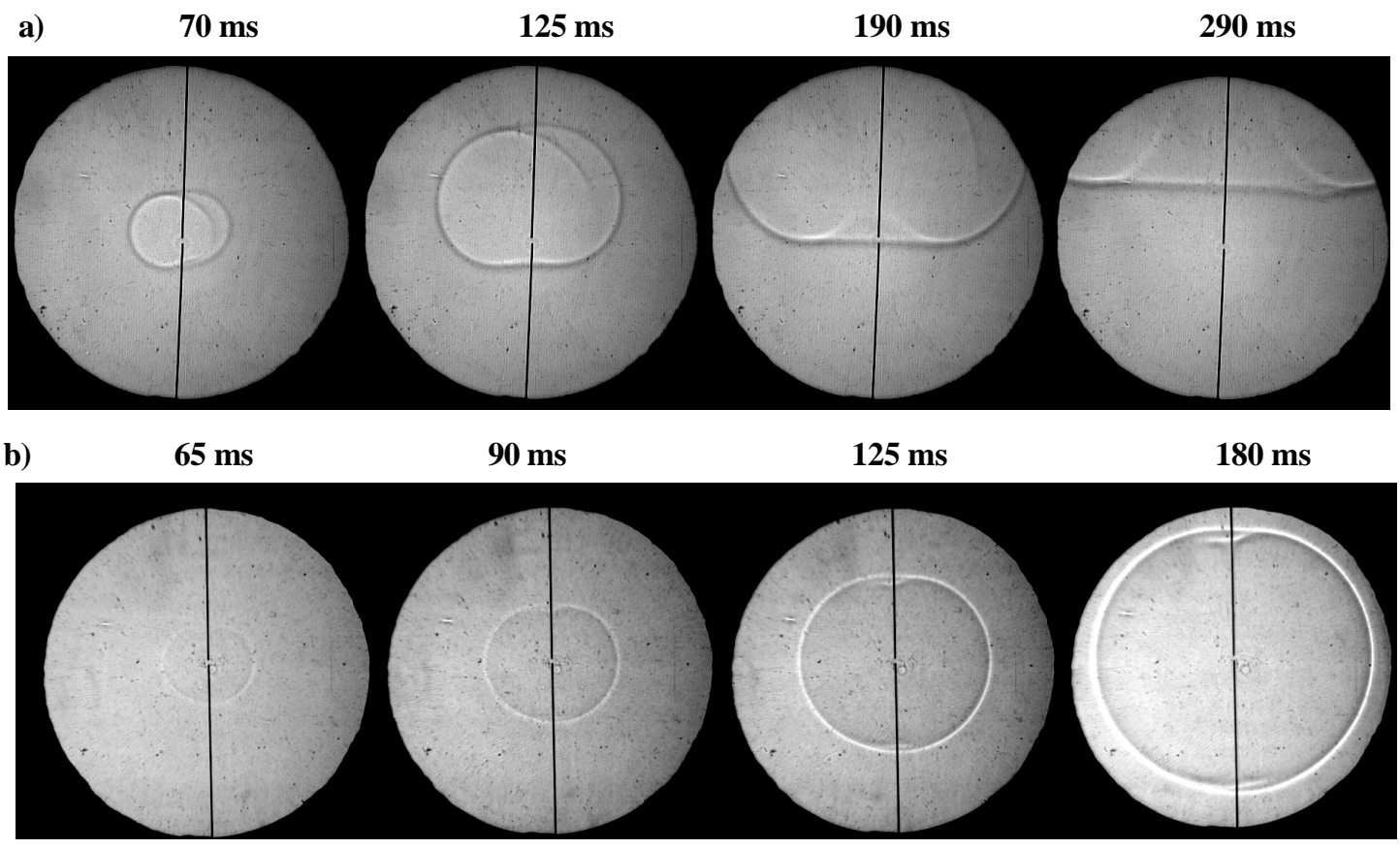

Figure 2. Burning sequences of stoichiometric $\mathrm{H}_{2} / \operatorname{Air} / 64 \% \mathrm{~N}_{2}$ flames $\left(\mathrm{H}_{2}: \mathrm{O}_{2}: \mathrm{N}_{2}=2: 1: 15.78\right)$ at 1atm after ignition: a) 1-g; b) $\mu$-g. (From Ref. 36.) 
even propagate downward against the flow induced by buoyancy. As a result, experiments in microgravity become essential for measuring the near-limit flame properties. A typical example is shown in Fig. 2, corresponding to 1-g and $\mu$-g realizations of a stoichiometric hydrogen-air mixture with $64 \% \mathrm{~N}_{2}$ dilution. At 1 -g the burned gases are seen to move upward to form a classical mushroom shape, while in $\mu-\mathrm{g}$ the flame remains smooth and spherical. The present microgravity experiments thus permit accurate measurements of the flame radius $r_{f}(t)$ up to the extinction limit. This in turn allows accurate determination of the laminar burning velocity $S_{L}$ and the flame stretch $K$ via $(1 a, b)$ and the unstretched laminar burning velocity $S_{L_{\infty}}$ via (2).

\section{B. Flame Instabilities}

Three kinds of flame surface instabilities were observed during present experiments, as follows: preferential diffusion instability (only observed when $\mathrm{Ma}<0$ ), hydrodynamic instability (observed for all values of Ma) and buoyancy-induced instability. The presence of preferential-diffusion instability could be identified by irregular (chaotic) distortions of the flame surface relatively early in the flame propagation process. Preferentialdiffusion instability was invariably observed when Markstein numbers were negative. Fortunately, flame surfaces remained smooth at small flame radii even for conditions that involved preferential-diffusion instability so that laminar burning velocities could be measured for a time even at these conditions. Hydrodynamic instability could be identified by the development of a somewhat regular cellular disturbance pattern on the flame surface, very similar to the observations of $\mathrm{Groff}^{26}$; fortunately, these instabilities were only observed for flame diameters larger than 60 $\mathrm{mm}$ so that they did not affect present measurements that were limited to flame diameters that were smaller than 60 $\mathrm{mm}$. Finally, buoyant instabilities by distortion of the flame surface from a spherical shape as well as by upward motion of the centroid of the flame were observed for near-limit flames in normal gravity during previous work $^{18}$. However, they were not observed in the present microgravity investigation due to the elimination of buoyancy.

It is well known that lean $\mathrm{H}_{2}$ /Air flames are intrinsically unstable while rich $\mathrm{H}_{2}$ /Air flames are stable based on classical models of flame instability due to effects of preferential diffusion proposed by Manton et al. ${ }^{12}$ and Markstein ${ }^{13}$, namely, laminar premixed flames are unstable to effects of preferential diffusion at conditions where the fast-diffusion component $\left(\mathrm{H}_{2}\right.$ in the present instance) is deficient (at fuel-lean conditions in the present instance). According to previous studies ${ }^{18-20}$, stoichiometric combustion of hydrogen and air presents nearly-neutral preferential-diffusion instability. In the following, we discuss how the addition of various suppressants affects the preferentialdiffusion instabilities of hydrogen/air flames in terms of Markstein numbers. Measurements of Markstein numbers as a function of suppressant concentrations for stoichiometric $\mathrm{H}_{2}$ /air flames at

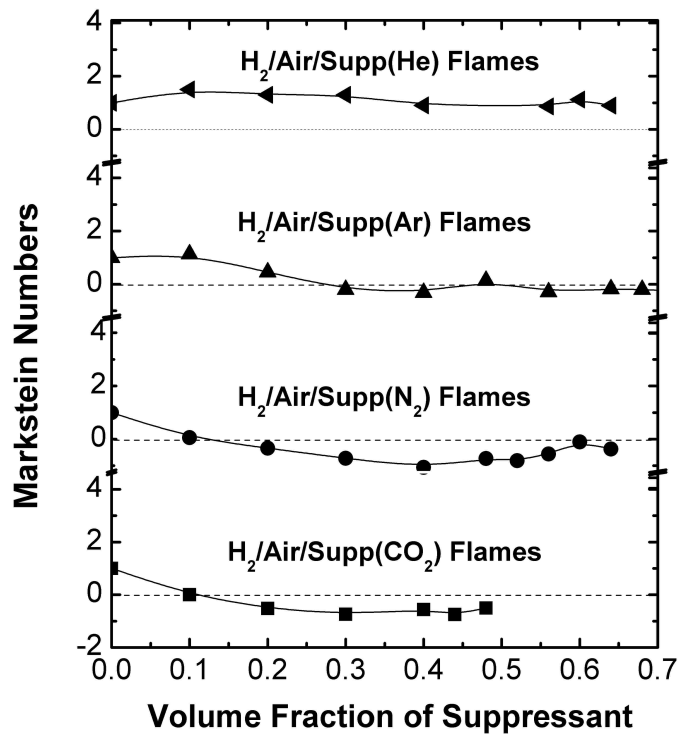

Figure 3. Measured Markstein numbers as functions of the volume fraction of helium, argon, nitrogen and carbon dioxide suppressants for premixed stoichiometric hydrogen/air flames at a 1 atm pressure. NTP are illustrated in Fig. 3, considering helium, argon, nitrogen and carbon dioxide as suppress ants. With the exception of helium, values of the Markstein number generally become progressively more negative as the concentration of suppressant increases. In these cases, preferential-diffusion instability is promoted as the flames become more suppressed. Results for helium as a suppressant differ from this behavior, however, because the transport properties of helium-diluted flames are 
significantly different from those of nitrogen/argon/carbon dioxide-diluted flames, e.g., the mass diffusivity in increased $\left(D_{u}=158.7 \mathrm{~mm}^{2} / \mathrm{s}\right.$ for heliumdiluted flames at NTP) but a more significant effect is the increase of thermal diffusivity of the mixture in the helium-diluted environment through the enhanced thermal conductivity of helium (roughly five times larger than that of nitrogen in the temperature range 300$3000 \mathrm{~K})$. The large thermal conductivity of the fastdiffusing helium molecules tends to promote preferential quenching of the reaction zone and thus stability of the flames to preferential diffusion/stretch interactions.

Measurements of Markstein numbers as a function of suppressant concentrations for $\mathrm{H}_{2} / \mathrm{EVA}$ prepation conditions for $\phi=1.0$ and room

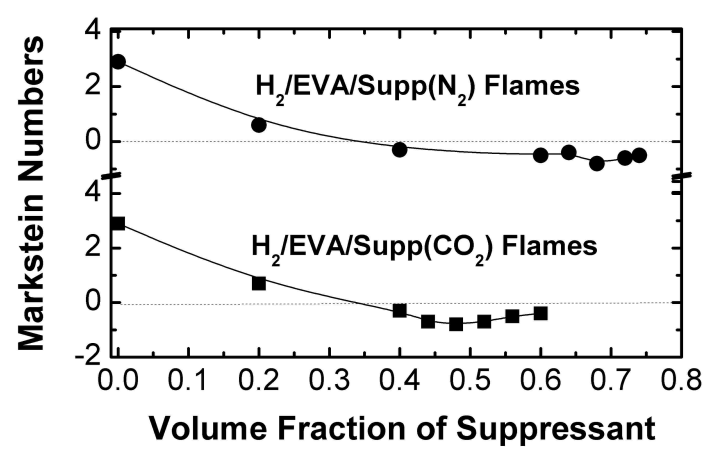

Figure 4. Measured Markstein numbers as functions of the volume fraction of nitrogen and carbon dioxide suppressants for premixed stoichiometric hydrogen/EVA flames at a pressure of $0.7 \mathrm{~atm}$. temperature are illustrated in Fig. 4, considering nitrogen and carbon dioxide as suppressants. These results are qualitatively similar to results in Fig. 3. Notably, for both of Figs. 3 and 4, the tendency for the addition of suppressants (except helium) to reduce the Markstein number for a given reactant mixture and thus promote the preferential-diffusion instability was slightly reversed at large concentrations of suppressant where extinction were approached, shown in Figs 3 and 4.

As an example of unstable and stale flames, Fig. 5 shows the shadowgraph photographs of two near-limit flames - stoichiometric $\mathrm{H}_{2} / \mathrm{air}$ flames at NTP having carbon dioxide and helium suppressants respectively, both at a concentration of 50\% in volume in the reactant mixture. The former yields an unstable flame while the latter yields a stable flame. As mentioned above, stoichiometric combustion of hydrogen and air presents nearly-neutral preferential-diffusion instability. The difference between these two figures is that one with $\mathrm{CO}_{2}$ as suppressant which tends to decrease Markstein number and one with He as suppressant which tends to increase Markstein number. The smooth and spontaneously wrinkled flame surfaces for stable and unstable preferential-diffusion conditions are clear evident in Fig 5 due the reasons above. When it is noted that wrinkled unstable flames have increased burning velocities compared to smooth flames having the same laminar burning velocities, (because wrinkled flame surfaces have more surface area for reaction ${ }^{27}$ ), the results of Fig. 5 clearly demonstrate a potentially undesirable effect of $\mathrm{CO}_{2}$ as a flame suppressant with respect to fire safety.

\section{Burning Velocities}

The short-drop free-fall facility was used

to measure the unstretched laminar burning velocities $S_{L_{\infty}}$ of stoichiometric hydrogen-air flames for each suppressant type and concentration as described above. The $S_{L_{\infty}}$ values measured at atmospheric pressure are shown in Fig. 6, with corresponding results for the EVA atmosphere shown in Fig. 7. Results are given as functions of the suppressant volume fraction, with the corresponding computed values shown for comparison. The oxygen index, also shown in the lower axis, is the volume fraction of oxygen in the reactant mixture as a percentage of the non-fuel 
gases. The measured values of $S_{L_{\infty}}$ for suppressant volume fractions below $40 \%$ are from previous 1 -g experiments ${ }^{4}$. Since the burning velocities in those cases generally exceed $20 \mathrm{~cm} / \mathrm{s}$, gravity effects can be neglected and direct comparisons with the present $\mu$-g results can be made. For suppressant volume fractions above $40 \%$, in most cases the 1-g flame was not sufficiently spherical to obtain meaningful values of the flame radius $r_{f}(t)$ and thus laminar burning velocities are reported only from the $\mu$-g measurements. The uncertainties in the measured $S_{L_{\infty}}$ values are shown by $95 \%$ confidence intervals.

The results in Fig. 6 show that all suppressants cause $S_{L_{\infty}}$ to decrease as the suppressant concentration is increased. The relative effectiveness for the suppressants, defined by the reduction of the unstretched laminar burning velocity at any fixed suppressant concentration, increases in order from helium to argon, nitrogen and carbon dioxide, with the latter being most effective. For argon, nitrogen, and carbon dioxide the observed trend can be explained by the simple increase in the specific heat of the non-fuel gases per unit oxygen concentration ${ }^{18}$. This causes a corresponding reduction in the reaction zone temperatures of these flames, and an associated reduction in their laminar burning velocities ${ }^{28}$. However helium represents an exception, since its specific heat is identical to that of argon, and thus demonstrates that the simple specific-heat effect alone cannot account for the observed relative suppressant effectiveness. For helium, the reduction in flame speed produced by the specific-heat effect is partly offset by the increase in heat and mass transfer rates into the reactant mixture from the substantially higher diffusivity of helium, which act to increase $S_{L_{\infty}}$ when helium is present. The specific-heat effect is dominant, since the suppressant effectiveness still increases with increasing helium concentration, but the net result is to render helium less effective than argon.
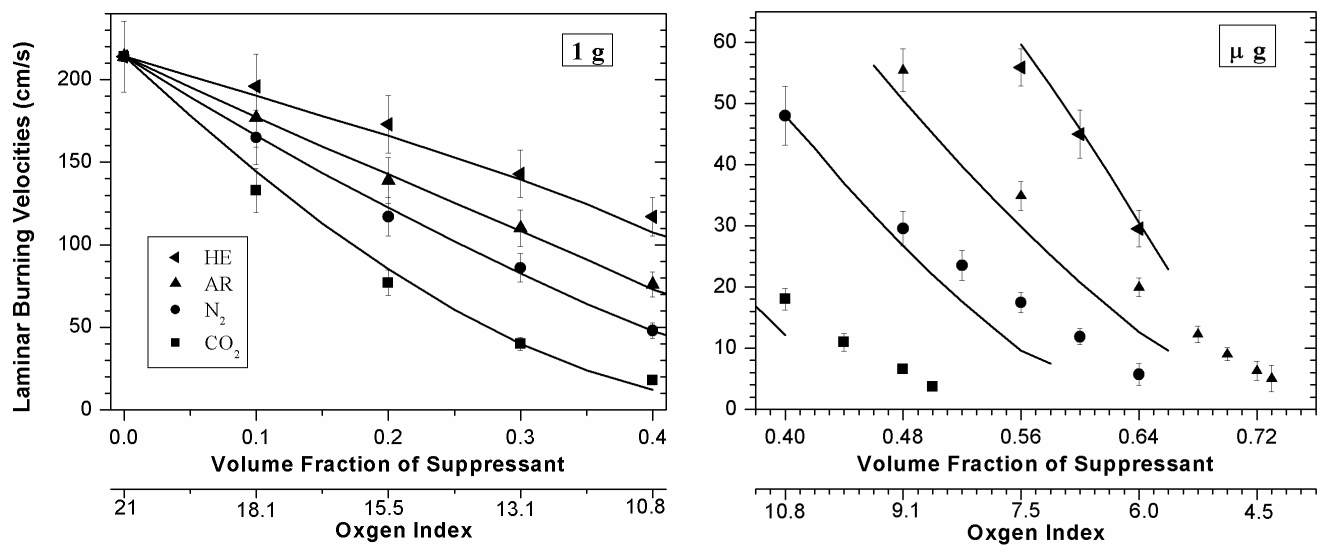

Figure 6. Measured (symbols) and computed (lines) planar laminar burning velocities as functions of the volume fractions of helium, argon, nitrogen and carbon dioxide suppressants for premixed stoichiometric hydrogen/air/suppressant flames at a pressure of 1 atm at $1-g$ and $\mu-g$. (From Ref. 36.)

For the EVA atmosphere in Fig. 7, the higher suppressant effectiveness of $\mathrm{CO}_{2}$ relative to $\mathrm{N}_{2}$, is consistent with the simple specific-heat effect noted above. As expected, the higher oxygen concentration (30\%) in the EVA atmosphere increases the resulting $S_{L_{\infty}}$ values relative to the corresponding cases in Fig. 6 . However the lower pressure in the EVA atmosphere reduces the mass-burning rate at the same $S_{L_{\infty}}$ value. The net result is that, for the same suppressant type and concentration, the mass-burning rates are only about $10 \%$ larger in the EVA atmosphere in Fig. 6 than for the air atmosphere in Fig. 7. 

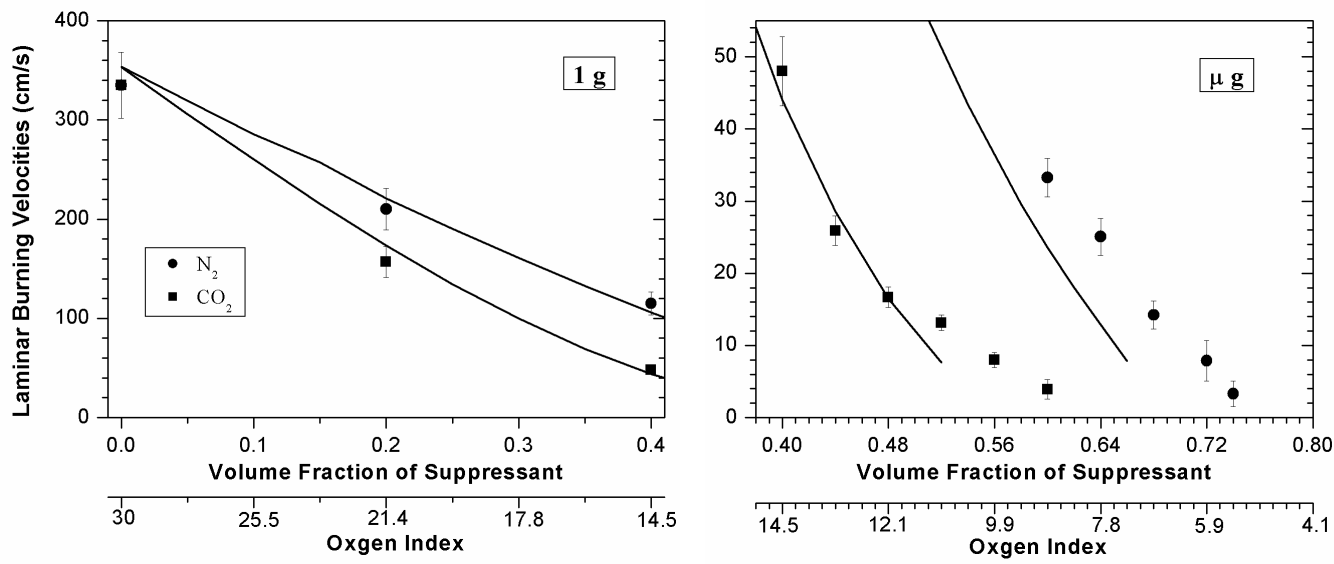

Figure 7. Measured (symbols) and computed (lines) planar laminar burning velocities as functions of the volume fractions of nitrogen and carbon dioxide suppressants for premixed stoichiometric hydrogen/EVA $\left(30 \% \mathrm{O}_{2}+70 \% \mathrm{~N}_{2}\right) /$ suppressant flames at a pressure of 0.7 atm at 1 -g and $\mu$-g. (From Ref. 36.)

\section{Flammability Limits}

Figures 6 and 7 show that for each suppressant there is a maximum concentration above which no flame will propagate in the present experiments. This is in direct disagreement with computational results ${ }^{29-30}$, which have suggested that there is no purely chemical flammability limit for unstretched laminar flames without heat losses, and that $S_{L^{\infty}}$ will instead decrease asymptotically to zero as the dilution by an inert suppressant increases. However practically all experimental studies of flammability limits have suggested that the laminar burning velocity at the flammability limit, Table 3. Flammability Limits of Hydrogen Flames: Suppressant Volume Fraction at $S_{\mathbf{L} 8}=0$. here denoted by $S_{L \infty, \mathrm{lim}}$, is not zero and instead is on the order of a few $\mathrm{cm} / \mathrm{s}$. The present results in Figs. 6 and 7 are consistent with this.

Despite many studies to date, there is no agreement on the true value of $S_{L \infty, \mathrm{lim}}$. If for the moment we accept the computational results that suggest $S_{L \infty, \text { lim }}=0$, then we can use the measured $S_{L_{\infty}}$ values in Figs. 6 and 7 to estimate the concentration of each suppressant needed to extinguish a hydrogen flame in air and EVA atmospheres. This is done by extrapolating the measured near-limit laminar burning velocities to determine where $S_{L \infty}$ would reach zero. The resulting extrapolated limits for stoichiometric $\mathrm{H}_{2}$ /Air and $\mathrm{H}_{2}$ /EVA flames are given in Table 3 in terms of the suppressant volume fraction in the reactant mixture, as well as the corresponding suppressant volume fraction in the non-fuel gases and the limiting oxygen index. The former suggests that $76 \% \mathrm{Ar}, 68 \% \mathrm{~N}_{2}$ or $53 \% \mathrm{CO}_{2}$ are needed by volume in the reactant mixture to extinguish a premixed $\mathrm{H}_{2} / \mathrm{Air}$ flame, and that $75 \% \mathrm{~N}_{2}$ or $64 \% \mathrm{CO}_{2}$ are needed to extinguish the corresponding $\mathrm{H}_{2} / \mathrm{EVA}$ flame. Although the extrapolation is based on a flammability limit criterion about which there remains some uncertainty, the purpose is to estimate the amount of suppressant needed to guarantee extinction of a hydrogen flame, which is an essential quantity for practical spacecraft fire safety applications.

The practical significance of the above estimate demonstrates the fundamental importance of accurately determining the true nature of the extinction limit for laminar premixed flames. As noted above, computational 
results ${ }^{20,21}$ have suggested $S_{L \infty, \text { lim }}=0$, while experimental results including those in Figs. 6 and 7 suggest that the

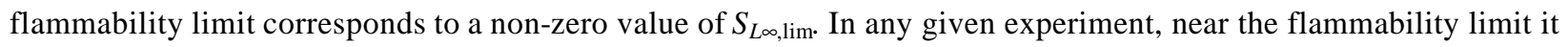
is likely that small disturbances produced by buoyant convection or hydrodynamic strain could potentially account for the observed non-zero extinction limits. Additionally, heat losses in most experiments due to radiation or conduction could also cause the observed non-zero extinction limits ${ }^{31}$. However in the present mic rogravity experiments, buoyant convection and hydrodynamic strain have been essentially eliminated, as noted above. Moreover, the $180 \mathrm{~mm}$ radius of the present spherical chamber is sufficiently large in comparison with the $r_{f}<30$ $\mathrm{mm}$ flames for heat losses by conduction to the walls or to the $250 \mu \mathrm{m}$ tungsten electrodes to also be negligible. This suggests that, in the present experiments, radiative heat loss to the chamber wall is likely to be the sole remaining experimental factor that could realistically account for the observed non-zero values of $S_{L \infty, \text { lim }}$ in Figs. 6 and 7.

\section{E. Flame structures}

To gain a better understanding of the addition of suppressants on the structures of laminar premixed flames, numerical simulations of plane (unstretched) $\mathrm{H}_{2}$ /air flames in the presence of various suppressants were carried out using PREMIX. Figure 8 shows the predicted structures of plane unstreteched $\mathrm{H}_{2} /$ air flames with and without suppressants at fuel-equivalence ratio of unity and NTP. Results in Fig. 8 a) provide the baseline flame structure when no suppressant is present. Fig. 8 b)-d) provide similar results for the flames with a high suppressant concentration (50\% helium, argon, and nitrogen by volume). All these results are based on the hydrogen/oxygen chemical kinetics mechanism of $\mathrm{Li}^{11}$. In each figure, the top graph provides profiles of temperature and the stable species $\left(\mathrm{H}_{2}, \mathrm{O}_{2}\right.$ and $\left.\mathrm{H}_{2} \mathrm{O}\right)$ concentrations, whereas the bottom graph provides profiles of radical species $(\mathrm{H}, \mathrm{OH}, \mathrm{O}$, $\mathrm{H}_{2} \mathrm{O}$ and $\mathrm{H}_{2} \mathrm{O}_{2}$ ) concentrations, all as a functions of distance through the flame. The results show that the maximum concentrations of the radicals $\mathrm{HO}_{2}$ and $\mathrm{H}_{2} \mathrm{O}_{2}$ are much smaller than the concentrations of the radicals $\mathrm{H}$ and $\mathrm{OH}$, and $\mathrm{O}$; therefore, the latter tend to dominate reactive effects in the present flames. Obviously, due to the dilution caused by the suppressants having initial concentrations of $50 \%$, the reactant concentrations $\left(\mathrm{H}_{2}\right.$ and $\left.\mathrm{O}_{2}\right)$ and product concentration $\left(\mathrm{H}_{2} \mathrm{O}\right)$ are decreased for the suppressed flames comparing to the unsuppressed flame. An interesting trend shown in Fig. 8 is that the concentration of $\mathrm{O}_{2}$ near the cold boundary of the flame increases before it decreases once again upon approach to the reaction zone of the flame. This effect is due to the preferential diffusion of fastdiffusing reactant, $\mathrm{H}_{2}$, compared to the slow-diffusing reactant, $\mathrm{O}_{2}$ for a plane flame. The next major trend is the progressive reduction of the final flame temperature form $2250 \mathrm{~K}$ (for no suppressant) to $1665 \mathrm{~K}$ (for the suppressant $\mathrm{He}$ and $\mathrm{Ar}$ ), and to $1440 \mathrm{~K}$ (for the diatomic suppressant $\mathrm{N}_{2}$ ). This behavior is solely due to the progressive increase of specific heat of these suppressants in the order of $\mathrm{He}$ and $\mathrm{Ar}$ (the same) and $\mathrm{N}_{2}$. On the other hand, the increased thermal diffusivity of He compared to Ar has no effect on the final flame temperature because these flames are adiabatic. For the present stoichiometric flames, the radical $\mathrm{H}$ generally has the largest maximum concentrations in the flames, with $\mathrm{OH}$ having somewhat smaller maximum concentrations, e.g., roughly 1/4 $-1 / 3$ as large as $\mathrm{H}$, and with the other radicals all having significantly smaller concentrations. In addition, the maximum concentration of $\mathrm{H}$ in the flames progressively decreases in the order no suppressant, helium, argon and nitrogen. Similarly, but not shown here, the maximum concentrations of $\mathrm{H}$ in the flame for a particular reactant mixture progressively decreases with increasing concentrations of suppressants. Based on the findings of Kwon and Faeth ${ }^{32}$, for flames having hydrogen and oxygen as reactants, it is expected that this reduction of the maximum concentration of $\mathrm{H}$ should cause a corresponding reduction of the laminar burning velocity of these flames.

\section{F. Discrepancies in Computed Burning Velocities}

There is evidence that shortcomings in the chemical kinetic mechanism may be at least partly responsible for differences between the measured and computed results in Figs. 6 and 7. The respective $S_{L_{\infty}}$ values are seen to agree reasonably well at low suppressant concentration, but to diverge at higher concentrations as the observed extinction limits are approach. For the hydrogen-air flame with $56 \% \mathrm{~N}_{2}$ dilution, the computed $S_{L_{\infty}}$ is only about half of the measured value. Consistent with this, Wu et al. ${ }^{33}$ have previously found that standard chemical kinetic mechanisms 
a)
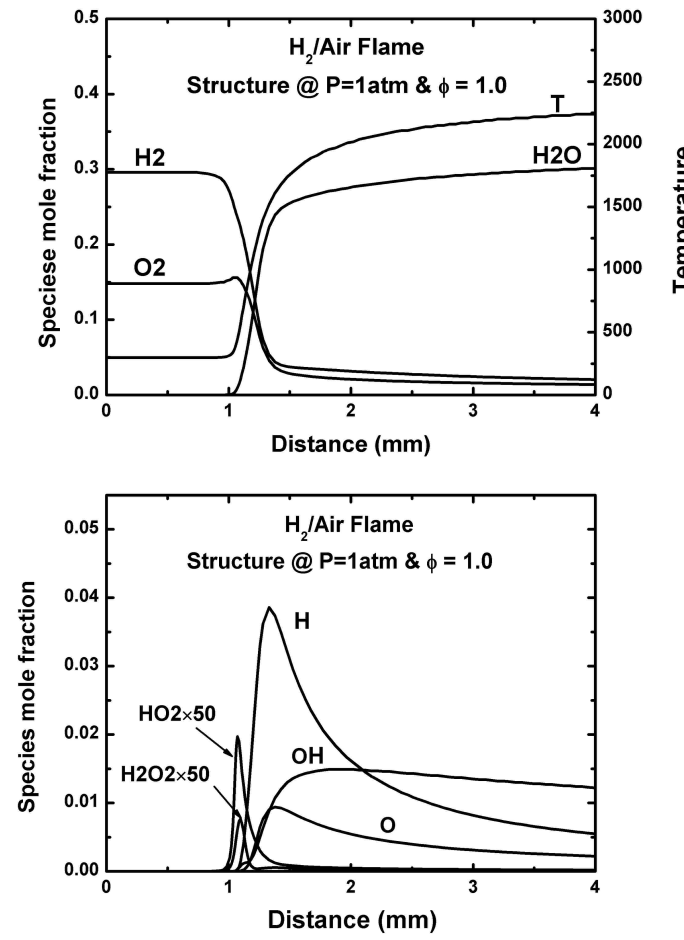

c)
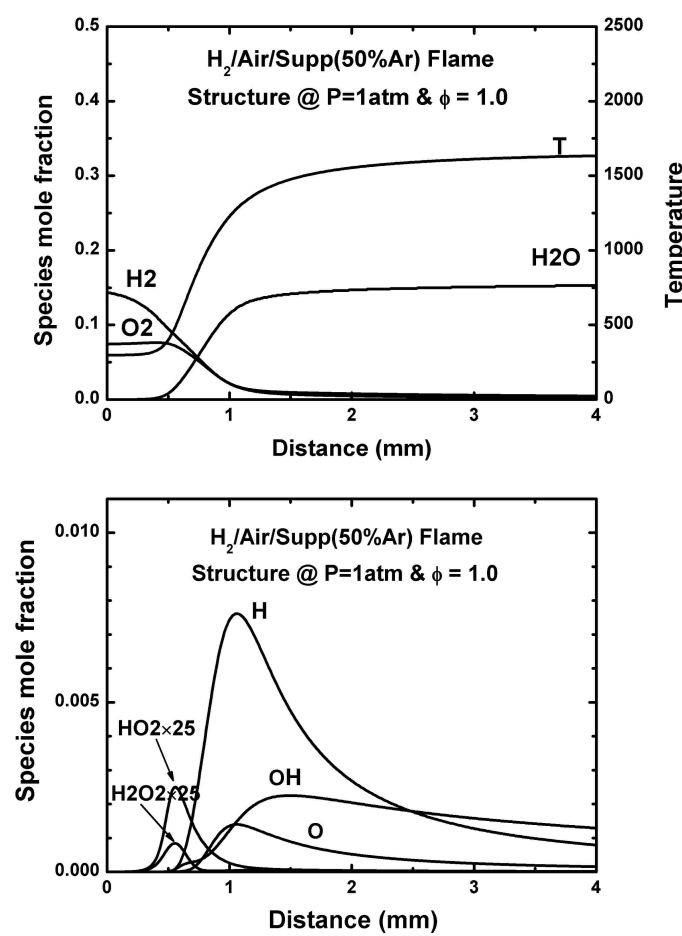

b)
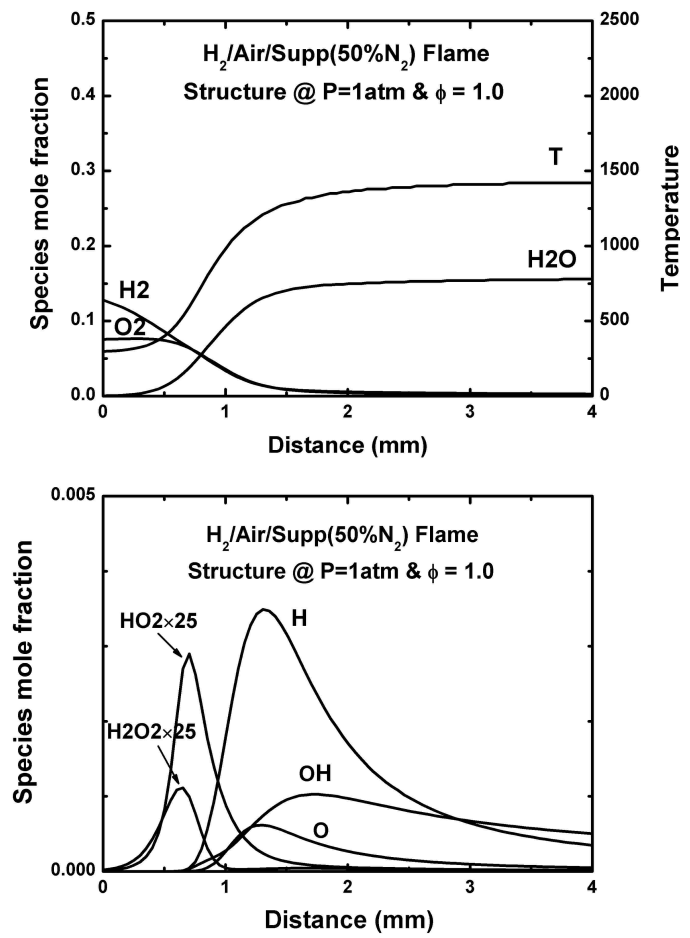

d)
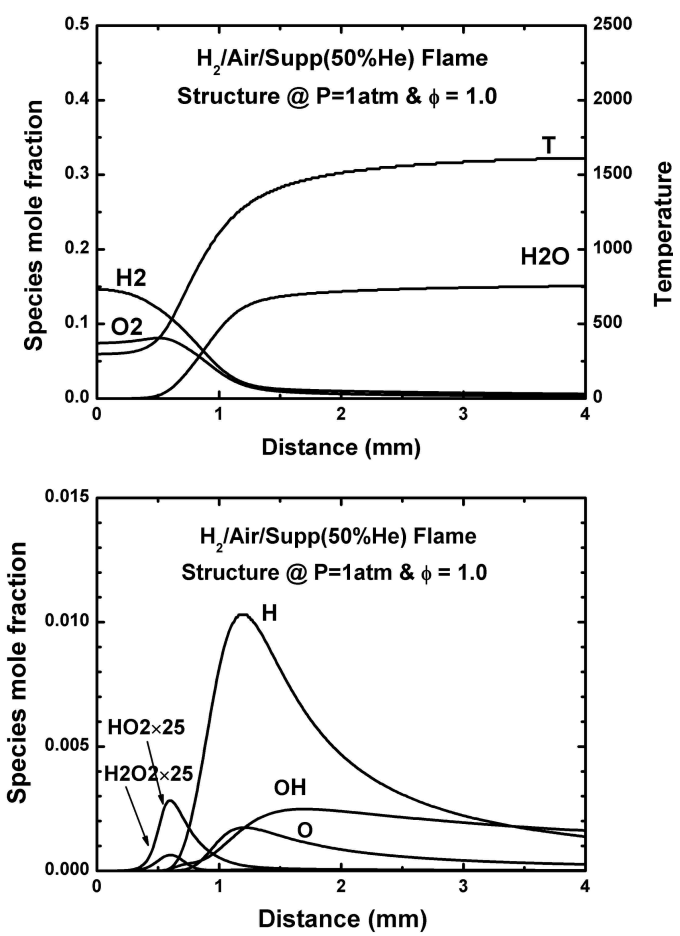

Figure 8. Predicted structure of an premixed stoichiometirc hydrogen/air flames at NTP: a) without suppressant, b) with a $50 \%$ by volume nitrogen suppressant, c) with a $50 \%$ by volume argon suppressant, d) with a $50 \%$ by volume helium suppressant. 
yield smaller flame balls, lower flame speeds, and richer flammability limits than do measurements. Egolfopoulos and $\mathrm{Law}^{34,35}$ also found that the standard kinetic mechanisms underpredict the flame speed for strained premixed hydrogen-air flames as the fuel equivalence ratio is decreased. Factors such as modeling of molecular transport mechanisms and radiation heat losses of near-limit flames could all be possible contributors to these discrepancies. Here we will examine if the present observations suggest that improvements may be needed in the chemical mechanism to produce accurate computed results for nearlimit flames.

To identify the most important near-limit elementary reactions, a sensitivity analysis of $S_{L_{\infty}}$ respect to reaction rate coefficients was performed for stoichiometric $\mathrm{H}_{2} / \mathrm{EVA}$ flames diluted with $40 \%, 60 \%$ and $66 \% \mathrm{~N}_{2}$ by volume. The results, shown in Fig. 9, indicate that the chainpropagation and chain-branching reactions have positive sensitivities on $S_{L_{\infty}}$ while the chain-termination reactions have negative sensitivities. Increasing the $\mathrm{N}_{2}$ volume fraction increases the corresponding sensitivities, yielding the largest sensitivities at the largest $\mathrm{N}_{2}$ volume fraction. For the $40 \% \mathrm{~N}_{2}$ flame, two-body chain branching reactions are dominant. For the near-limit $66 \% \mathrm{~N}_{2}$ flame, the sensitivity to the three-body chain-termination reaction $\mathrm{H}+\mathrm{O}_{2}+\mathrm{M}=\mathrm{HO}_{2}+\mathrm{M}$ becomes comparable with the sensitivity to the chain-branching reactions. This indicates that, as the extinction limit is approached, this chaintermination reaction increasingly controls the flame.

Figure 9 suggests the possibility that a substantial part of the discrepancy between the measured and computed

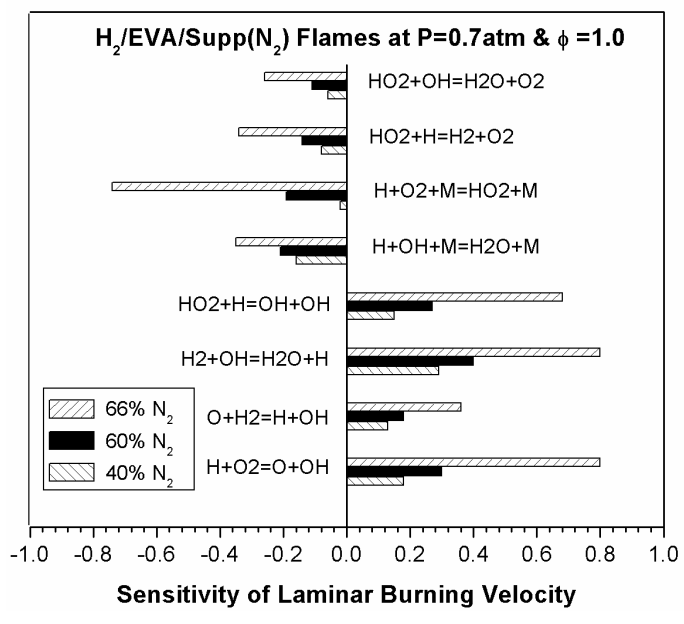

Figure 9. Sensitivity coefficients of laminar burning velocity with respect to reaction rate coefficients, computed for stoichiometric $\mathbf{H} / \mathbf{E V A}$ flames having $40 \% \quad \mathrm{~N}_{2}, 60 \% \quad \mathrm{~N}_{2}$ and $66 \% \quad \mathrm{~N}_{2}$ as suppressants at $0.7 \mathrm{~atm}$ respectively using the kinetics of Li et al. (2003). (From Ref. 36.)

$S_{L \infty}$ values in Figs. 6 and 7 may be due to the three-body recombination rates for $\mathrm{H}+\mathrm{O}_{2}+\mathrm{M}=\mathrm{HO}_{2}+\mathrm{M}$ reactions, and in particular to the third-body chaperon efficiency of various species $M$. This is made even more likely by the fact that for the present measured values considerable care has been taken to reduce imperfections in the experiments that might otherwise be relied on to account for this difference. The $\mathrm{H}+\mathrm{O}_{2}+\mathrm{M}=\mathrm{HO}_{2}+\mathrm{M}$ recombination reactions are extremely important for highly-diluted near-limit flames, due to the competition between chain-branching and chain-terminating reactions near the flammability limit. This is consistent with the increasing discrepancies in Figs. 6 and 7 between measured and computed $S_{L_{\infty}}$ values as the suppressant concentrations are increased, and suggests potential value in measurements and computations to better define the third-body efficiencies in this key reaction.

\section{Conclusions}

This study investigated the effects of various chemically-passive suppressants on the near-limit properties of laminar premixed hydrogen flames in microgravity both experimentally and computationally. The measurements were conducted in a novel short-drop free-fall microgravity facility at the University of Michigan, involving unsteady outwardly propagating spherical laminar premixed hydrogen flames. Experimental and computational conditions considered premixed hydrogen/air/suppressant and hydrogen/30\% oxygen and 70\% nitrogen/suppressant flames, with the latter condition of interest for EVA-preparation activities onboard manned spacecraft. The other flame conditions were as follows: room temperature $(298 \mathrm{~K})$; fuel equivalence ratio of unity; pressures of 1.0 and 0.7 atm; chemically-passive gaseous suppressants including helium, argon, nitrogen and carbon dioxide; and suppressant concentration of $40 \%$ to the extinction limit. The near-limit unstretched laminar burning velocities and the flame response to stretch, characterized by Markstein numbers, were accurately measured for varying concentrations of suppressants in stoichiometric hydrogen-air and hydrogen-EVA flames. The computed flame 
behavior considered variable transport and thermodynamics properties, multi-component transport, radiation heat loss, and the detailed hydrogen/oxygen chemical kinetic mechanism of $\mathrm{Li}^{22}$.

Chemically-passive flame suppressants perform in order of increasing effectiveness from helium, to argon, nitrogen and carbon dioxide, which mainly reflects their progressively increasing specific heats and progressively decreasing mass and thermal transport properties. The volume fraction of each suppressant required to extinguish stoichiometric $\mathrm{H} / \mathrm{Air}$ or $\mathrm{H} / \mathrm{EVA}$ flames, estimated by extrapolating the measured near-limit laminar burning velocities to zero, was found to be $76 \% \mathrm{Ar}, 68 \% \mathrm{~N}_{2}$ or $53 \% \mathrm{CO}_{2}$ by volume in the reactant mixture for the $\mathrm{H}_{2} / \mathrm{Air}$ flame, and $75 \% \mathrm{~N}$ or $64 \% \mathrm{CO}_{2}$ for the $\mathrm{H} / \mathrm{EVA}$ flame. There is a consistent tendency for the addition of suppressants to reduce the Markstein number for a given reactant mixture at the same time that the unstretched laminar burning velocity is reduced. Thus the tendency of suppressants to reduce laminar burning velocities (and thus to reduce the severity of unwanted fires) is counteracted to some extent by the tendency of suppressants to reduce Markstein numbers and promote flame instabilities.

Computed values for the unstretched laminar burning velocities using current chemical kinetic mechanisms were found to be in good agreement with corresponding measured values far from the extinction limit. However the computed values become substantially lower than the measured values at large suppressant concentrations as the flammability limit is approached, even though considerable care has been taken to reduce imperfections in the present experiments that might otherwise account for these differences. The increasing sensitivity of the burning velocity to the three-body chain-termination reactions $\mathrm{H}+\mathrm{O}_{2}+\mathrm{M}=\mathrm{HO}_{2}+\mathrm{M}$ as the extinction limits is approached suggests that possible improvements in the third-body chaperon efficiencies may be needed to reconcile computed flammability limits with the present measured values.

\section{Acknowledgements}

This research was supported by NASA Grant No. NNC04GA08G, with Dr. F. Takahashi of NASA Glenn Research Center serving as program manager.

\section{References}

${ }^{1}$ Walravens, B., BattinLeclerc, F., Come, G. M., Baronnet, F., "Inhibiting Effect of Brominated Compounds on Oxidation Reactions," Combustion and Flame, Vol. 103, 1995, pp 339-342.

${ }^{2}$ Miziolek, A. W., and Tsang, W., Halon Replacement: Technology and Science, American Chemical Society, Washington, DC, 1995, pp 322.

${ }^{3}$ Linteris, G. T. and Truett, L., "Inhibition of Premixed Methane-Air Flames by Fluoromethanes," Combustion and Flame, Vol. 105 No. 1-2, 1996, pp 15-27.

${ }^{4}$ Faeth, G. M., Kim, C. H., and Kwon, O. C., "Mechanisms of Fire Suppression by Halons and Halon Replacements: A Review, " Clean Air, Vol. 4, 2003, 115-186.

${ }^{5}$ Linteris, G. T., Burgess, D. R., Babushok, V., Zachariah, M., Tsang, W., and Westmoreland, P., "Inhibition of Premixed Methane-Air Flames by Fluoroethanes and Fluoropropanes," Combustion and Flame, Vol. 113, 1998, pp 164-180.

${ }^{6}$ Prasad, K., Li, C., Kailasanath, K., Ndubizu, C., Ananth, R., and Tatem, P. A., "Numerical Modeling of Water Mist Suppression of Methane-Air Diffusion Flames," Combustion Science and Technology, Vol. 132, No. 1-6, 1998 pp 325.

${ }^{7}$ Milne, T. A., Green, C. L., and Benson, D. k., "The Use of the Counterflow Diffusion Flame in Studies of hhibition Effectiveness of Gaseous and Powdered Agents," Combustion and Flame, Vol. 15, 1970, pp 255-264.

${ }^{8}$ Seshadri, K., and Ilincic, N., "The Asymptotic Structure of Inhibited Nonpremixed Methane-Air Flames," Combustion and Flame, Vol. 101, 1995, pp 271-294.

${ }^{9}$ Ronney, P. D., "Effect of Gravity on Laminar Premixed Gas Combustion I: Flammability Limits and Burning Velocities," Combustion and Flame, Vol. 62, No. 2, 1985, pp 107-119.

${ }^{10}$ Ronney, P. D., "Effect of Chemistry and Transport Properties on Near-Limit Flames at Microgravity," Combustion Science and Technology, Vol. 59, 1988, pp 123-141.

${ }^{11}$ Olson, S. L., and T'ien, J. S., "A Theoretical Analysis of the Extinction Limits of a Methane-Air Opposed-Jet Diffusion Flame," Combustion and Flame, Vol. 70, No. 2, 1987, pp 161-170.

${ }^{12}$ Manton, J., von Elbe, G., and Lewis, B., "Nonisotropic Propagation of Combustion Waves in Explosive Gas Mixtures and Development of Cellular Flames," Journal of Chemical Physics, Vol. 20, No. 1, 1952, pp. 153-158.

${ }_{13}^{13}$ Markstein, G. H., Non-Steady Flame Propagation, Pergamon, New York, 1964, p. 22.

${ }^{14}$ Strehlow, R. A., and Savage, L. D., "The Concept of Flame Stretch," Combustion and Flame, Vol. 31, No. 2, 1978, pp. 209211. 
${ }^{15}$ Clavin, P., "Dynamic Behavior of Premixed Flame Fronts in Laminar and Turbulent Flows," Progress in Energy and Combustion Science, Vol. 11, No. 1, 1985, pp. 1-59.

${ }^{16}$ Law, C. K., "Dynamics of Stretched Flames," Proceedings of the Combustion Institute, Vol. 22, 1988, pp. 1381-1402.

${ }^{17}$ Vagelopoulos, C. M., Egolfopoulos, F. N., and Law, C. K., "Further Considerations on the Determination of Laminar Flame Speeds with the Counterflow Twin Flame Technique," Proceedings of Combustion Institute, Vol. 25, 1994, pp 1341-1347.

${ }^{18}$ Qiao, L., Kim, C. H., and Faeth, G. M., "Suppression Effects of Diluents on Laminar Premixed Yydrogen/Oxygen/Nitrogen Flames," Combustion and Flame, Vol. 143, No.1-2, 2005, pp 79-96.

${ }^{19}$ Aung, K. T., Hassan, M. I., and Faeth, G. M., "Flame/Stretch Interactions of Laminar Premixed Hydrogen/Air Flames at Normal Temperature and Pressure," Combustion and Flame, Vol. 109, No. 1/2, 1997, pp. 1-24.

${ }^{20}$ Tseng, L.-K., Ismail, M. A., and Faeth, G. M., "Laminar Burning Velocities and Markstein Numbers of Hydrocarbon/Air Flames," Combustion and Flame, Vol. 95, No. 4, 1993, pp. 410-426.

${ }^{21}$ McBride, B. J., Reno, M. A., and Gordon, S., "CET93 and CETPC: An Interim Updated Version of the NASA Lewis Computer Program for Calculating Complex Chemical Equilibrium with Applications", NASA TM 4557, 1994.

${ }^{22}$ Li, J., Zhao, Z., Kazakov, J., and Dryer, F. L., "An Updated Comprehensive Kinetic Model of Hydrogen Combustion", International Journal of Chemical Kinetics. Vol. 36, No. 10, 2004, pp 566-575.

${ }^{23}$ Kee, R. J., Rupley, F. M., and Miller J. A., “The CHEMKIN Thermodynamic Data Base”, Report No. SAND87-8215B, Sandia National Laboratories, 1992.

${ }^{24}$ Kim, T. J., Yetter, R. A., and Dryer, F. L., "New Results on Moist CO Oxidation: High Pressure, High Temperature Experiments and Comprehensive Modeling," Proceedings of the Combustion Institute, Vol. 25, 1994, pp. 759-766.

${ }^{25}$ Kuznetsov, V. R., and Sabelnikov, V. A., Turbulence and Combustion. Hemisphere Publishing Corporation, New York, 1990.

${ }^{26}$ Groff, E. G., "The Cellular Nature of Spherical Propane-Air Flames," Combustion and Flame, Vol. 48, No. 1, 1982 , pp. 51-62.

${ }^{27}$ Aung,K. T., Hassan, M. I., Kwon, O. C., Tseng, L.-K., and Faeth, G.M., "Flame/Stretch Interactions in Laminar and Turbulent Premixed Flames," Combustion Science and Technology, Vol. 173, No. 1, 2002, pp. 61-99.

${ }^{28}$ Huggett, C., "Combustion Processes in the Aerospace Environment," Aerospace Medicine, Vol. 40, 1969, pp. $1176-1180$.

${ }^{29}$ Lakshmisha, K. N., Paul, P.J., and Mukunda, H. S., "On the Flammability Limit and Heat Loss in Flames with Detailed Chemistry," Proceedings of Combustion Institute, Vol. 23, 1990, pp 433-440.

${ }^{30}$ Giovangigli, V., and Smooke, M., "Extinction of Strained Premixed Laminar Flames with Complex Chemistry," Combustion Science and Technology, Vol. 87, 1992, pp 241-256.

${ }^{31}$ Williams, F. A., Combustion Theory, 2nd ed., Beijiamin-Cummins, Menlo Park, 1985.

${ }^{32}$ Kwon, O. C., and Faeth, G. M., "Flame/Stretch Interactions of Premixed Hydrogen-Fueled Flames: Measurements and Predictions," Combustion and Flame, Vol. 124, No. 4, 2001, pp. 590-610.

${ }^{33}$ Wu, M.-S., Liu, J. B. and Ronney, P. D., "Numerical Simulation of Diluent Effects on Flame Ball Structure and Dy namics," Proceedings of the Combustion Institute, Vol. 27, 1998, pp. 2543-2550.

${ }^{34}$ Egolfopoulos F. N., and Law, C. K., "A Kinetic Criterion of Flammability Limits: The C-H-O-Inert System," Proceedings of the Combustion Institute, Vol. 23, 1990, pp 413-421.

${ }^{35}$ Egolfopoulos F. N., and Law, C. K., "Chain Mechanisms in the Overall Reaction Orders in Laminar Flame Propagation," Combustion and Flame, Vol. 80, No. 1, 1990, pp 7-16.

${ }^{36}$ Qiao, L., Gu, Y., Dahm, W. J.A., Oran, E., and Faeth, G. M., "Near-Limit Laminar Burning Velocities of Microgravity Premixed Hydrogen Flames with Chemically-Passive Fire Suppressants", Proceedings of the Combustion Institute, Vol. 31, 2006, submitted. 